\title{
Effects of Chronic Furosemide Treatment and Age on Cell Division in the Adult Gerbil Inner Ear
}

\author{
H. Lang, ${ }^{1}$ B. A. Schulte, ${ }^{1,2}$ And R. A. Schmiedt ${ }^{1}$ \\ ${ }^{1}$ Department of Otolaryngology and Head-Neck Surgery, Medical University of South Carolina, Charleston, SC 29425, USA \\ ${ }^{2}$ Department of Pathology and Laboratory Medicine, Medical University of South Carolina, Charleston, SC 29425, USA
}

Received: 17 December 2001; Accepted: 29 August 2002; Online publication: 17 December 2002

\section{ABSTRACT}

Atrophy of the stria vascularis and spiral ligament and an associated decrease in the endocochlear potential (EP) are significant factors in age-related hearing loss (presbyacusis). To model this EP decrease, furosemide was delivered into the round-window niche of young adult gerbils by osmotic pump for seven days, chronically reducing the $\mathrm{EP}$ by $30-40 \mathrm{mV}$. Compound action potential (CAP) thresholds were correspondingly reduced by 30-40 dB SPL at high frequencies. Two weeks after withdrawal of furosemide, the treated ears showed an EP recovery of up to 20-30 $\mathrm{mV}$ along with a similar recovery of CAP thresholds. The influence of cell division on furosemide-induced and age-related decline of the EP was examined using a mitotic tracer, bromodeoxyuridine (BrdU). Cell proliferation was examined in three groups: young control, furosemide-treated, and aged cochleas. Sections immunostained for BrdU were bleached with $\mathrm{H}_{2} \mathrm{O}_{2}$ to eliminate ambiguities with melanin pigment in the inner ear. Cell types positively labeled for BrdU in all three groups included Schwann cells in Rosenthal's canal; glial cells in the osseous spiral lamina; fibrocytes in the limbus, sacculus, and spiral ligament (SL); epithelial cells in Reissner's and round-window membranes; intermediate cells in the stria vascularis; and vascular endothelial cells. Quantitative analysis showed that the mean number of BrdU-positive (BrdUt) intermediate cells in the stria did not differ significantly among

Correspondence to: R. A. Schmiedt - Department of Otolaryngology, Head and Neck Surgery - Medical University of South Carolina? Walton Research Bldg. 39 Sabin St., Rm 608 - Charleston, SC 29425. Telephone: (843) 792-7977; fax: (843)-792-7736; email: schmiera@musc.edu the three groups. In contrast, there was a significant increase of BrdU + fibrocytes in the SL of furosemidetreated animals as compared to the young control group. Moreover, there was a significant decrease in labeled fibrocytes in the aged versus the young ears, particularly among the type II and type IV subtypes. The results suggest that the increased fibrocyte turnover in the SL after furosemide treatment may be related to the recovery of EP and CAP thresholds, supporting the hypothesis that fibrocyte proliferation may be essential for maintaining the EP and cochlear function in normal and damaged cochleas. Moreover, the decreased turnover of SL fibrocytes with age may be a contributing factor underlying the lateral wall pathology and consequent EP loss that often accompanies presbyacusis.

Keywords: cochlea, furosemide, BrdU, aging, fibrocytes, spiral ligament, endocochlear potential

\section{INTRODUCTION}

An important factor in the onset of age-related hearing loss is degeneration of the spiral ligament and stria vascularis within the lateral wall of the cochlea (Schuknecht and Gacek 1993; Spicer et al. 1997). The degeneration of these tissues leads to a decrease of the endocochlear potential (EP) which in turn raises hearing thresholds especially at high frequencies (Sewell 1984; Schulte and Schmiedt 1992; Schmiedt and Schulte 1992; Gratton et al. 1996, 1997; Schmiedt et al. 2000, 2002). Furosemide blocks the secretory $\mathrm{Na}-\mathrm{K}-2 \mathrm{Cl}^{-}$cotransporter (NKCC1) and decreases the EP (Forge 1976; Rybak 1985; Ikeda et al. 
1997). We have developed a young-gerbil model of presbyacusis by using an osmotic pump to deliver furosemide chronically to one cochlea (Schmiedt et al. 1999, 2000, 2002; Schmiedt and Lang 2001). The physiological results presented here demonstrate that hearing thresholds in the furosemide-treated gerbils can recover to almost normal after cessation of the chronic infusion. The recovery process is novel and its basis is unknown.

Furosemide is thought to block ion transport in those cells in the lateral wall that are known to express NKCC1 (Crouch et al. 1997; Sakaguchi et al. 1998), like certain subtypes of fibrocytes in the spiral ligament and marginal cells in the stria vascularis. The fibrocytes and marginal cells play an important role in regulating ion homeostasis in the cochlea and critically support the generation of the EP. Fibrocytes in the spiral ligament have been classified into five types according to their location, morphology, and histochemical properties (Spicer and Schulte 1991, 1996). Moreover, subclasses of these fibrocytes are known to degenerate with age (Spicer et al. 1997; Sakaguchi et al. 1998; Hequembourg and Liberman 2001).

Roberson and Rubel (1994) and Yamashita et al. (1999) have shown that spiral ligament fibrocytes undergo mitosis in response to acoustic trauma and aminoglycoside insult in young gerbils and mice, respectively. Consideration of the above results led to the hypothesis that the recovery of the EP and hearing thresholds after furosemide treatment might be related to the ability of the affected cells to proliferate after injury. In this article we address this question by assessing change in cell proliferation under conditions of chronic furosemide treatment and senescence.

\section{MATERIALS AND METHODS}

\section{Animal and surgical procedures}

Mongolian gerbils were born and raised in a lownoise environment where the median sound level was $40 \mathrm{~dB}$ SPL. Both genders were used in these experiments. Six gerbils at 35-37 months of age were used in the quiet-age group. For the furosemide group, 16 six-month-old animals were implanted with Alzet ${ }^{\circledR}$ mini-osmotic pumps (model 2004, Durect, Cupertino, CA) and cannulas leading to the right ear. Untreated left ears were used as controls. These pumps have a fill volume of about $200 \mu \mathrm{l}$ and a mean pumping rate of $0.25 \mu \mathrm{l} / \mathrm{h}$ at $37^{\circ} \mathrm{C}$. Cannulas were made up of surgical-grade silicon tubing. Pumps were filled with 5 or $10 \mathrm{mg} / \mathrm{ml}$ furosemide under sterile conditions and allowed to equilibrate at $37^{\circ} \mathrm{C}$ for $36-$ $48 \mathrm{~h}$ before implantation.

\section{Experimental Protocol}

\section{Physiological studies}

\section{A. Furosemide, no recovery \\ Pump implanted Pump removed

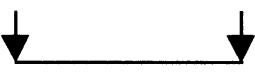 \\ Days $1 \quad 7$ Physiology}

\section{B. Furosemide, with recovery}

Pump implanted Pump removed

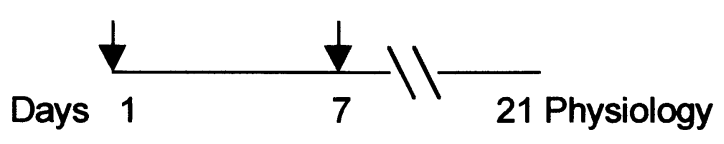

\section{Morphological studies}

\section{A. Furosemide-treated gerbils \\ Pump implanted Pump removed BrdU injected

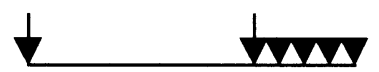 \\ Days $1 \quad 7891011$ Fix}

\section{B. Aged gerbils}

\section{BrdU injected}

\section{Days $\quad \frac{1234}{123}$ Physiology, Fix}

FIG. 1. Timeline of the experimental protocols. Downward arrows indicate pump implantation or removal; downward arrowheads indicate BrdU injection.

Surgery for pump implantation was done under sterile conditions. Animals were anesthetized with sodium pentobarbital $(50 \mathrm{mg} / \mathrm{kg})$ and were given atropine $(0.2 \mathrm{mg} / \mathrm{kg})$ to reduce the respiratory secretions. The pump was placed subdermally behind the scapulae and the cannula routed to the bulla. The cannula was threaded through holes in the bulla and into the round-window niche. The surface of the bulla was then sealed with dental cement. Pumps were left implanted for one week. None of the animals showed any signs of infection. The aged animals and some of the furosemide-treated gerbils were injected with single daily intraperitoneal doses of bromodeoxyuridine (BrdU, $100 \mathrm{mg} / \mathrm{kg}$, Sigma) for four 
days before sacrifice. Timelines of the BrdU injections are shown in Figure 1. The animal procedures and facilities have full AAALAC and local IACUC accreditation and meet NIH guidelines for animal care.

\section{Physiological procedures}

The procedures for recording the CAP response and EP have been described previously (Schmiedt and Zwislocki 1977; Hellstrom and Schmiedt 1996; Schmiedt 1996; Schmiedt et al. 1996). The animal was anesthetized with sodium pentobarbital $(50 \mathrm{mg} / \mathrm{kg})$ and fitted to a head holder in a sound- and vibrationisolated booth. The booth was heated to maintain the cochlea at near body temperature $\left(36-37^{\circ} \mathrm{C}\right)$. The pinna and surrounding tissues were removed and the bulla opened widely. The CAP electrode was placed on the bony rim of the round-window niche, and the acoustic assembly, comprising a probe-tube microphone (B\&K 4134, Bruel and Kjaer, Norcross, GA) and driver (Beyer DT-48, Beyerdynamic, Farmingdale, NY), was sealed to the bony ear canal with closed-cell foam. The tone pips were generated in the frequency domain by TDT (Tucker Davis Technologies, Gainesville, FL) equipment and software, and the spectrum was normalized to the average ear canal SPL obtained from 30 gerbils. CAP thresholds were obtained visually at half-octave frequencies from 0.5 to $16 \mathrm{kHz}$ and at $20 \mathrm{kHz}$ with tone pips of $1.8 \mathrm{~ms}$ total duration with $\cos ^{2}$ rise/fall times of $0.55 \mathrm{~ms}$. Endocochlear potentials were recorded in cochlear turn 1 (T1), corresponding to a best frequency of about 16 $\mathrm{kHz}$ according to the single-fiber map of Müller (1996). EP microelectrodes were filled with $0.2 \mathrm{M} \mathrm{KCl}$ and had impedances ranging between 20 and $40 \mathrm{M} \Omega$. The EP was defined as the voltage difference between scala media and a pool of isotonic saline on the neck muscles. Electrode potentials were zeroed after each measure of EP. The timeline of the terminal physiological measures are also shown in Figure 1.

\section{Morphological procedures}

Anesthetized animals were perfused via cardiac catheter with $10 \mathrm{ml}$ of normal saline containing $0.1 \%$ sodium nitrite followed by $50 \mathrm{ml}$ of $4 \%$ paraformaldehyde in PBS. After piercing the round-window membrane, $1 \mathrm{ml}$ of fixative solution was gently perfused through the oval window. The temporal bones were then rapidly harvested and fixed for $6-8 \mathrm{~h}$; then they were decalcified with EDTA, dehydrated, embedded in paraffin, and sectioned serially at $5 \mu \mathrm{m}$ thickness for immunostaining.

Light microscopic immunostaining for BrdU on every fifth section was performed following previously described procedures (Lang et al. 2000). The tissue sections were deparaffinized, dehydrated, and immersed in a $1 \%$ hydrogen peroxide $/ 50 \%$ methanol solution for $30 \mathrm{~min}$ at room temperature to inactivate endogenous peroxidase. Tissues were treated with $100 \mu \mathrm{g} / \mathrm{ml}$ pepsin in $0.01 \mathrm{~N} \mathrm{HCl}$ for $25 \mathrm{~min}$ at $37^{\circ} \mathrm{C}$ to unmask aldehyde crosslinked antigens. The sections were denatured with $2 \mathrm{~N} \mathrm{HCl}$ in $0.05 \%$ Tween-20 in PBS for $30 \mathrm{~min}$ at $37^{\circ} \mathrm{C}$, neutralized in $0.1 \mathrm{M}$ sodium borate ( $\mathrm{pH} 8.5$ ) for $10 \mathrm{~min}$, and immersed in blocking solution for $20 \mathrm{~min}$. Sections were incubated overnight with a mouse anti-BrdU antibody (SigmaAldrich, St. Louis, MO) diluted 1:1000 in PBS at $4^{\circ} \mathrm{C}$. The secondary antibody was biotinylated antimouse IgG (1:150, Vector Laboratories, Burlingame, CA) and binding was detected with the avidin-biotinhorseradish peroxidase (HRP) technique using the Vectastain (Vector Laboratories, Burlingame, CA) ABC kit. HRP was visualized with 3,3'-diaminobenzidine tetrahydrochloride (DAB).

To bleach the melanocytes, the sections were incubated with $10 \% \mathrm{H}_{2} \mathrm{O}_{2}$ in PBS for $72 \mathrm{~h}$ at room temperature after BrdU immunostaining. Nuclei were counterstained with hematoxylin. BrdU+ cells were counted in every fifth section along the complete length of the cochlea. The total number of BrdU+ cells per ear was obtained by multiplying the actual counts by 5 and dividing by a correction factor of 1.3. The correction factor was determined as described previously (Hall 1990; Hall and Massengill 1997). The number of animals used for immunostaining studies is indicated in Figure 1. Sections were examined on a Zeiss Axioskop (Carl Zeiss, Jena, Germany) light microscope, and photographs were taken using a SPOT digital camera (Diagnostic Instruments, Sterling Heights, MI).

Five sections of the spiral ligament were sampled in the first turn of each cochlea to estimate cell density in the spiral ligaments. The number of type II and IV fibrocytes were counted in each section over an area of $100 \mu \mathrm{m} \times 170 \mu \mathrm{m}$ and then normalized to $\mathrm{mm}^{2}$ area (Fig. 9A).

\section{RESULTS}

Physiology

CAP thresholds and EP values obtained from ears used in the BrdU studies are shown in Figure 2. The mean thresholds of control ears (untreated left ears) are typical of data obtained from young gerbils in our $\mathrm{lab}$, as is the mean control EP of $94 \mathrm{mV}$ as measured in the basal turn (T1). Mean data from six ears exposed to furosemide for seven days are plotted along with mean data from four ears allowed to recover from the furosemide treatment for two weeks. The EP 


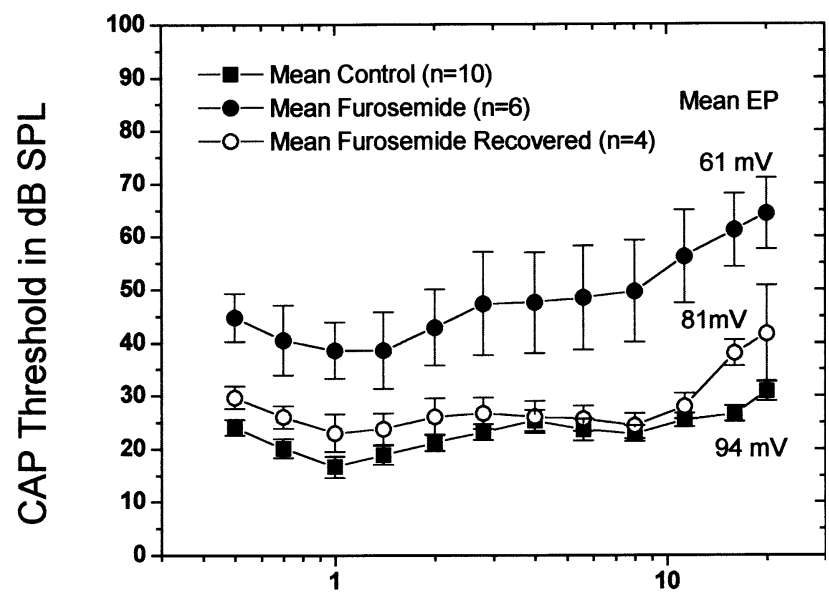

Frequency in $\mathrm{kHz}$

FIG. 2. Mean CAP thresholds and EP recorded in control and furosemide-treated ears. Error bars represent standard errors of the mean (SEM). Control data (solid squares) were obtained from the untreated left ears of both furosemide groups. Data from the sevenday treatment are plotted as filled circles, whereas data from animals similarly treated but allowed to recover for two weeks are plottedas open circles. The CAP thresholds and EP of the recovered group are similar to control data, with the largest differences seen at the highest frequencies.

reduction induced by furosemide resulted in a constant threshold shift of about $20 \mathrm{~dB}$ at frequencies below about $4 \mathrm{kHz}$, with increasing shifts at higher frequencies. The resulting profiles of CAP thresholds after furosemide treatment are similar to those previously reported in the quiet-aged gerbil (Schmiedt et al. 1990; Schmiedt 1993; Hellstrom and Schmiedt 1990, 1996). Ears allowed to recover for two weeks after furosemide treatment had thresholds similar to the mean control data except at the highest frequencies tested. The recovery of CAP thresholds above $4 \mathrm{kHz}$ paralleled the recovery of the EP to nearnormal values after furosemide treatment.

\section{Histochemistry}

Melanin bleaching of the inner ear. Following routine immunostaining procedures, numerous melanosomes and abundant melanin pigment were present in most sections of the stria vascularis (Fig. 3A), spiral ligament, modiolus, osseous spiral lamina, macula, ampulla, and semicircular canals and around the endolymphatic duct and sac in all three groups. Similar results have been seen for most other pigmented mammalian species (Wolff 1931; Savin 1965; La Ferriere et al. 1974; Hilding and Ginzberg 1977; Franz et al. 1990; Gratton and Wright 1992). There was a significant increase of melanin pigment in the stria vascularis, spiral ligament, and maculae of the aged inner ear (data not shown). However, there were no discernable changes in the level of melanin pigment in the furosemide-treated group as compared to young controls (data not shown). The large accumulations of melanin pigments in melanosomes were difficult to distinguish from the reaction product associated with BrdU immunostaining. To remedy this ambiguity, melanin pigment was effectively bleached by $10 \% \mathrm{H}_{2} \mathrm{O}_{2}$ (see Materials and Methods and Fig. 3). This procedure did not alter intensity of the oxidized DAB reactive product ( $\mathrm{Li}$ et al. 1999). The results for BrdU immunostaining reported below were performed on sections bleached in this manner.

Qualitative observations of cell division. Over 3400 sections from six furosemide-treated, six control, and five quiet-aged ears were examined in this study. The sections included the cochlea, the vestibular labyrinth, and the endolymphatic duct and sac. BrdU incorporation was seen in several cell types in all three groups of ears. These included Schwann cells in Rosenthal's canal; glial cells in the osseous spiral lamina; fibrocytes in the spiral ligament, limbus, and sacculus; epithelial cells in Reissner's and roundwindow membranes; intermediate cells in the stria vascularis (Figs. 3-5); and vascular endothelial cells (data not shown). Only a few nuclei in each ear (120) were labeled by the BrdU in most of these cell types, with the exception of fibrocytes in the spiral ligament. Labeled fibrocytes in the ligament were far more numerous than other cell types in all three groups of animals. No BrdU+ cells were seen in the neurosensory or supporting cells of the cochlea and vestibular end organs, in marginal and basal cells of the stria vascularis, nor in epithelial cells of the endolymphatic duct and sac.

\section{Quantitative analysis of cell division}

Figure $6 \mathrm{~A}$ shows the mean number of BrdU+ intermediate cells in the striae obtained from six furosemide-treated, six young control, and five aged animals. There were no significant differences among the three groups (one factor ANOVA, $p>0.05$ ).

On the other hand, as shown in Figure $6 \mathrm{~B}$, there was a significant increase in the number of BrdU+ fibrocytes in the spiral ligaments of furosemidetreated animals as compared to the young control group (one factor ANOVA, $p<0.01$ ). The mean number of labeled fibrocytes in the spiral ligament of the furosemide-treated ears was $448.3 \pm 108$, approximately four times that of the young controls ears $(110 \pm 20.5)$. There was also a significant decrease in the number of BrdU+ fibrocytes in the aged group $(42 \pm 9.3)$ as compared to young controls (one factor ANOVA, $p<0.01)$.

Fibrocytes in the spiral ligament have been classified into subtypes based on their location, morphology, and histochemical properties (Spicer and 


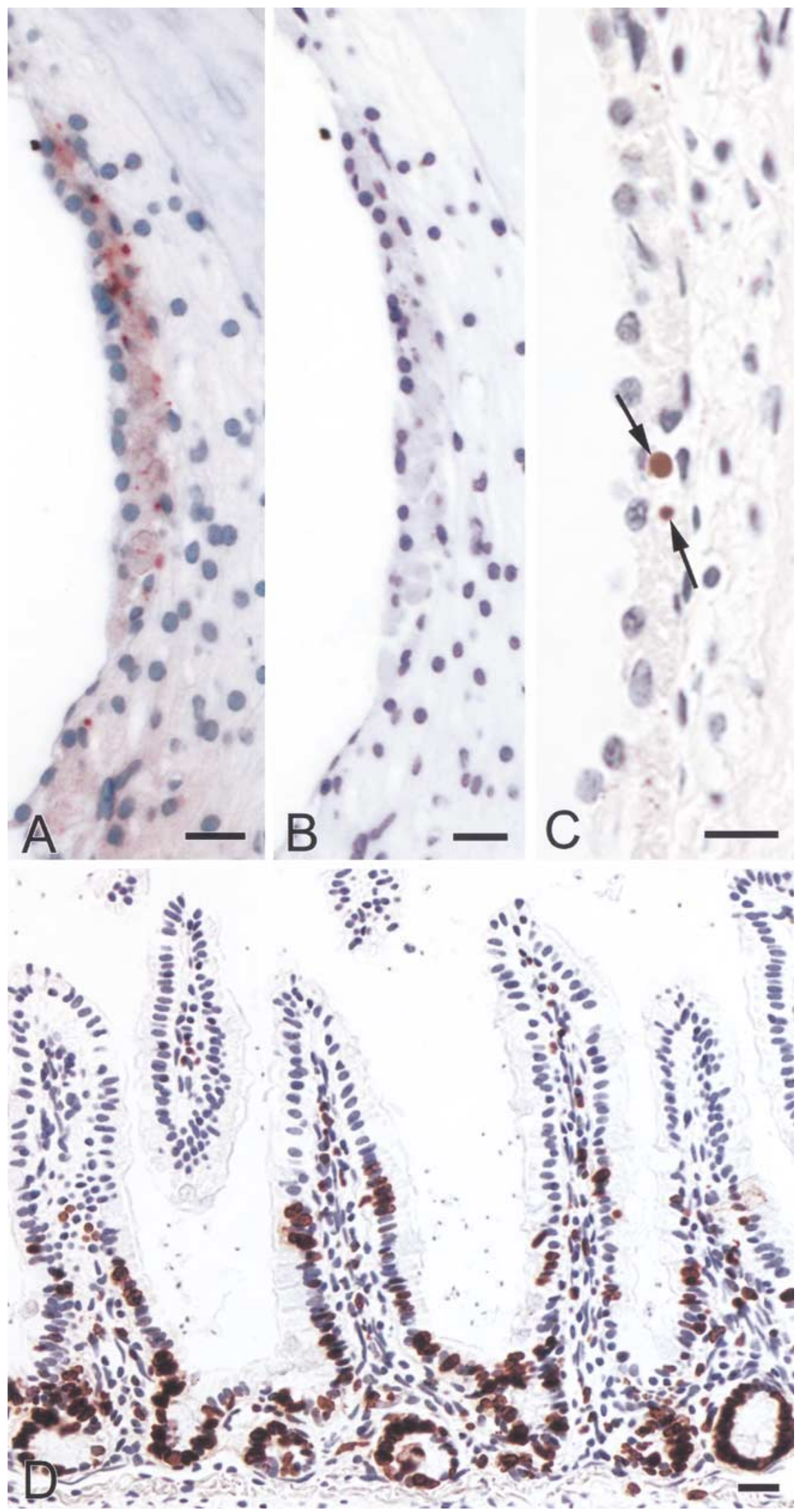

FIG. 3. A. Numerous melanosomes were present in strial intermediate cells, which made identifying BrdU+ cells problematic. B. Same section asshown in $\mathbf{A}$ after bleaching the melanin pigment with $\mathrm{H}_{2} \mathrm{O}_{2}$. C. Nuclei of two intermediate cells (arrows) are stained forBrdU in the bleached stria vascularis. D. Small intestine as a positive control shows a high-BrdU labeling index after bleaching. Bars $=25 \mu \mathrm{m}$. 


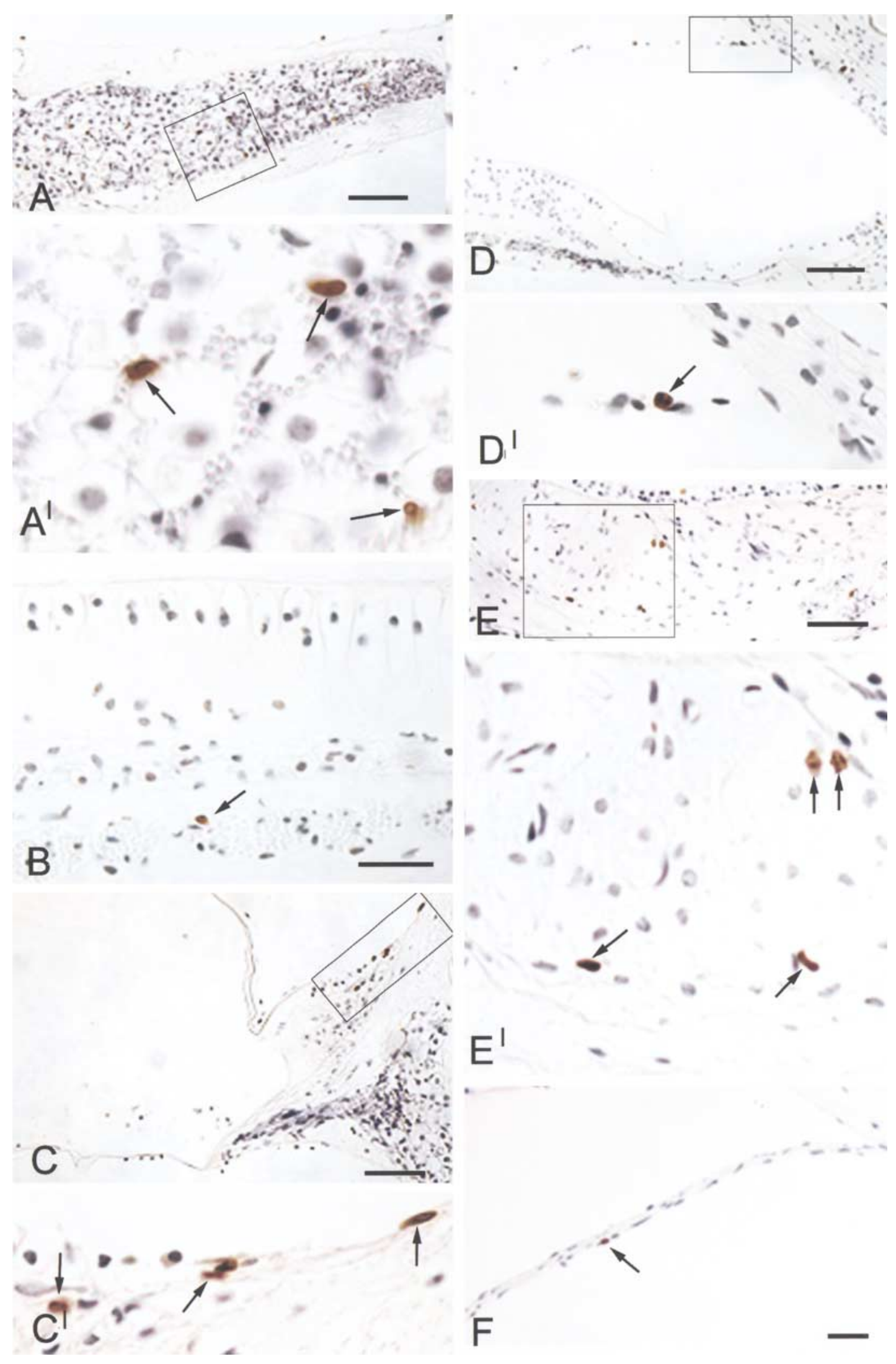

FIG. 4. BrdU staining of different cell types in the gerbil labyrinth. A. Low-magnification view of Rosenthal's canal. A'. Arrowsin higher magnification of boxed area in A point to three BrdU+ cells. B. Arrow points to a positively labeled cell in the osseous spiral lamina beneath the limbus. $\mathbf{C}^{\prime}$. Higher magnification of boxed area in $\mathbf{C}$ shows three BrdU+ cells (arrows). $\mathbf{D}^{\prime}$. Higher magnification of boxed

area in D shows a BrdU+ cell (arrow) in Reissner's membrane. $\mathbf{E}^{\prime}$. Higher magnification of boxed areain $\mathbf{E}$ shows four BrdU+ nuclei (arrows) in connective tissue under the utricular macula. F. Arrow points to a BrdU+ cell in the round-window membrane. Bars $=50$ $\mu \mathrm{m}$. 


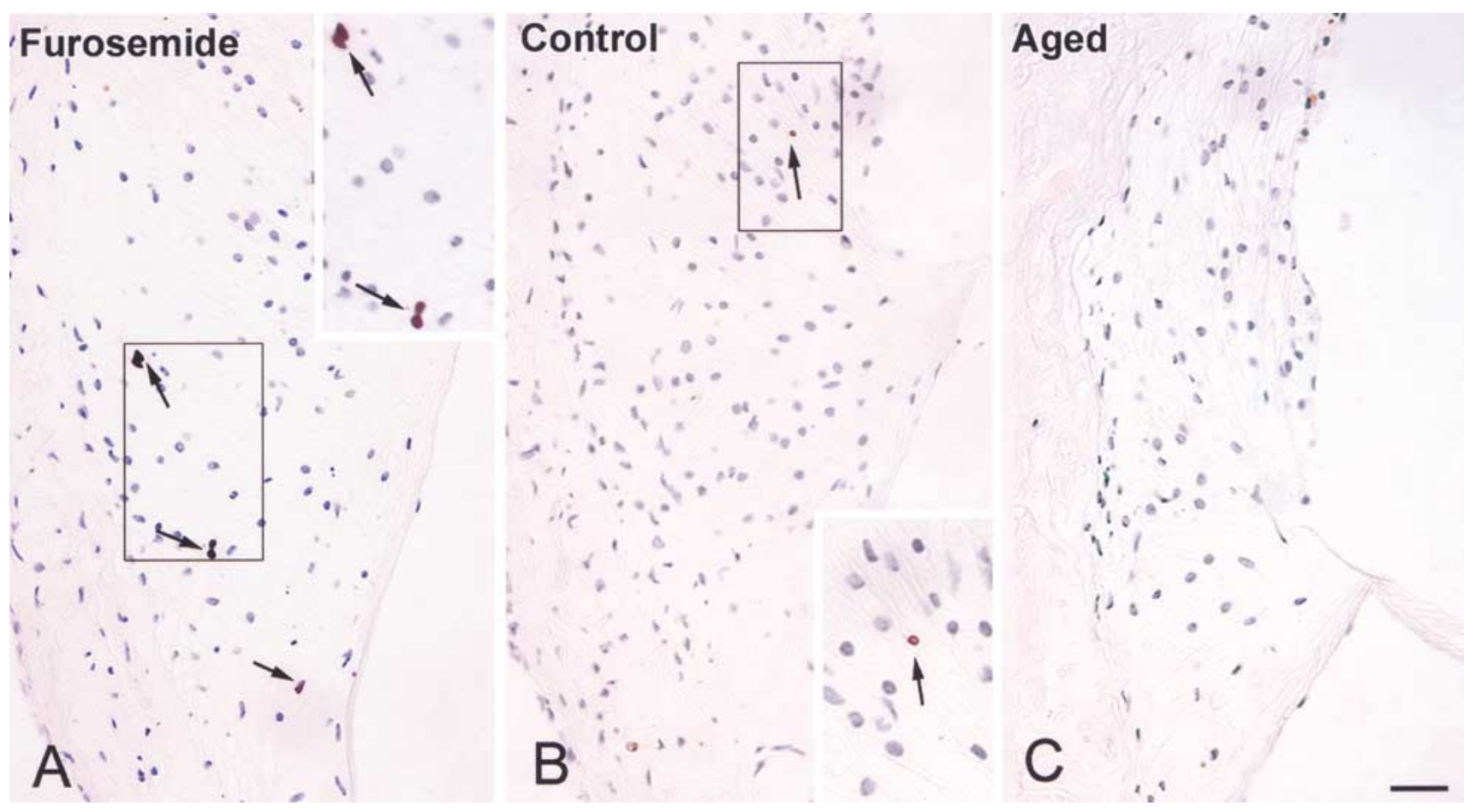

FIG. 5. BrdU+ cells in the spiral ligament (arrows). All sections are from the first turn. A. Five BrdU+ nuclei are present in the spiral ligament of a furosemide-treated cochlea. Higher-magnification inset of boxed area shows two pairs of BrdU+ cells. B. A BrdU+

Schulte 1991, 1996). The locations of these subtypes are illustrated in Figure 7. Given the significant differences in cell proliferation observed among the three groups of animals, subtypes of fibrocytes were further analyzed with respect to changes with furosemide treatment and age. The results are shown in Figure 8 . The numbers of mitotic cells per ear in all subtypes were significantly greater in furosemidetreated ears as compared to young controls. Differences with age, however, were only statistically significant for type II and type IV fibrocytes (Figs. 8A, B; ANOVA, $p<0.05)$.

Cell density is not taken into account in the data shown in Figures 6 and 8. A well-known consequence of aging is that cell numbers decline in many organs, including the cochlea. Thus, perhaps the differences in cell proliferation among the three animal groups seen above are caused by differences in cell density. To test this hypothesis, the densities of types II and IV fibrocytes in the lateral wall were determined for the three groups of animals (Fig. 9A). Indeed, there was a significant decrease in the cell density of type II and IV fibrocytes in aged ears as compared to young controls (ANOVA, $p<0.01$ ); however, there was no significant difference between furosemide-treated ears and young controls.

The raw numbers of mitotic type II and IV fibrocytes were normalized to their respective densities by nucleus in the spiral ligament of a young control cochlea is more clearly seen in the higher-magnification inset at bottom right. C. No BrdU + cells are present in this section of spiral ligament from an aged cochlea. Bar $=50 \mu \mathrm{m}$

dividing the average number of BrdU+ cells per ear (Fig. 8B) by the respective cell density (Fig. 9A). As shown in Figure 9B, there was still a significant decrease in the mitotic index of type II and IV fibrocytes in the aged ear as compared to young controls (ANOVA, $p<0.05$ ). There was also a significant increase in the normalized BrdU+ index of type II and IV fibrocytes in the furosemide-treated animals as compared to young controls (ANOVA, $p<0.05$ ). Thus, the significant differences seen in Figures 6 and 8 do not change when cell densities among the animal groups are taken into account.

\section{DISCUSSION}

Cell division in the ear

Ruben (1967) demonstrated with an radioautographic study in CBA-J mice that cell mitosis continued at least through postnatal day 7 (the oldest animal examined) in the stria vascularis, spiral ligament, Schwann cells, limbal stroma, and the epithelia of the basilar and Reissner's membranes. Roberson and Rubel (1994) observed dividing cells in the stria vascularis, glial cells among acoustic nerve fibers, and the spiral ligament of the 21-day-old gerbil. Cell division also has been reported in the spiral ligament of 4-5-week-old mice (Yamashita et al. 1999). Interme- 


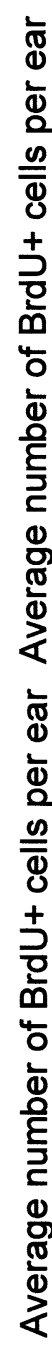

A

25

20

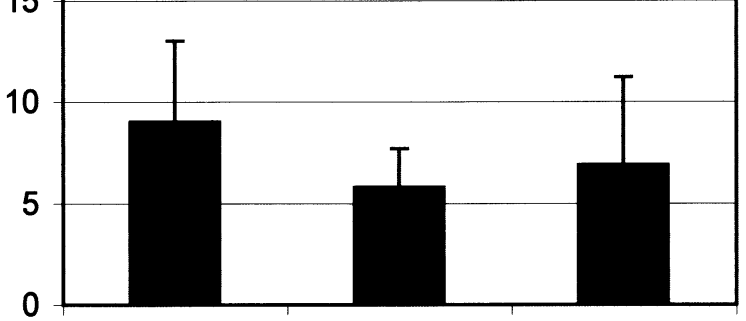

Furosemide

Control

Aged

FIG. 6. A. Intermediate cell-labeling indices in the bleached stria vascularis. Means $( \pm$ SEM) are from BrdU+ cell counts in six furosemide-treated, five aged, and six young control ears. There were no significant differences among the furosemide-treated, aged, and young control groups (ANOVA, $p>0.05$ ). B. Quantification of fibrocyte proliferation in the spiral ligament after bleaching. Means $( \pm$ SEM) are from same animals shown in A. Note the scale compared with A. The mean number of dividing fibrocytes in the furosemide group was significantly greater than in young controls; conversely, the mean number of proliferating fibrocytes in the aged group was significantly less than in young controls (ANOVA, $p<0.05$ ).

diate cells labeled by $\mathrm{BrdU}$ or ${ }^{3} \mathrm{H}$-thymidine have been seen in guinea pig aged 2-6 months (Conlee et al. 1994). To our knowledge this is the first study of general cell proliferation within the inner ear of mammals older than 6 months of age. The results demonstrate that several types of cells in the gerbil inner ear can continue to divide into old age. These cell types included the intermediate cells of the stria vascularis; glial cells among auditory nerve fibers; Schwann cells in Rosenthal canal; fibrocytes in the spiral ligament, limbus, and sacculus; and epithelial cells lining Reissner's and the round-window membranes.

\section{Effects of chronic furosemide treatment}

Many ${ }^{3} \mathrm{H}$-thymidine- or BrdU-labeled nuclei have been reported in the spiral ligament of the cochlea after acoustic or dihydrostreptomycin-mediated injuries (Roberson and Rubel 1994; Yamashita et al. 1999). A main finding here is that furosemide, when applied chronically to the round window of the gerbil cochlea, can significantly increase the proliferation of fibrocytes in the spiral ligament. Furosemide is a selective inhibitor of NKCC1 and, when administrated systemically, promotes ultrastructural changes in the stria vascularis and a reversible decrease in the EP (Forge 1976; Sewell 1984; Rybak 1985). In this study, chronic furosemide treatment for one week decreased EP to about $30 \mathrm{mV}$ lower than that found in the normal control cochlea. Ultrastructural studies of similarly treated ears showed increased interstitial space surrounding intermediate cells and intermediate cell degeneration in the stria vascularis. But little atrophy was found in spiral ligament (Okamura et al. 2000). The increase of fibrocyte proliferation in the spiral ligament found in this study may reflect a coping response of the cochlea, i.e., an effort to maintain the EP at a physiological level in the presence of furosemide (Schmiedt et al. 2002).

EP recovery after furosemide treatment and fibrocyte proliferation in the spiral ligament

Like some cells in other connective tissues, fibrocytes have the capacity to divide over their lifetime. However, the functional roles of fibrocytes in the inner ear are not fully understood. One hypothesis is that fibrocytes in the spiral ligament help maintain inner-ear ion and fluid homeostasis (Takahashi and Kimura 1970; Schulte and Adams 1989; Spicer and Schulte 1991; 1996; Spicer et al. 1997). Several enzymes involved in ion transport have been shown to be differentially expressed in the various subtypes of spiral ligament fibrocytes. These enzymes include NKCC1, $\mathrm{Na}, \mathrm{K}-\mathrm{ATPase}$, creatine kinase isozyme BB (CK), and carbonic anhydrase isozyme II (CA) (Schulte and Adams 1989; Spicer and Schulte 1991; Crouch et al. 1997; Spicer et al. 1997; Sakaguchi et al. 1998). Gap junctions are present among the fibrocytes and, along with the ion-transporter enzymes, are thought to play an active role in $\mathrm{K}^{+}$recycling in the ear (Kikuchi et al. 1995; 2000; Spicer and Schulte 1996). Moreover, Minowa and colleagues (1999) have demonstrated that the POU3F4 mouse mutant has a reduced EP associated with ultrastructural abnormalities in spiral ligament fibrocytes, providing additional evidence that these cells are fundamental to normal cochlear function. 


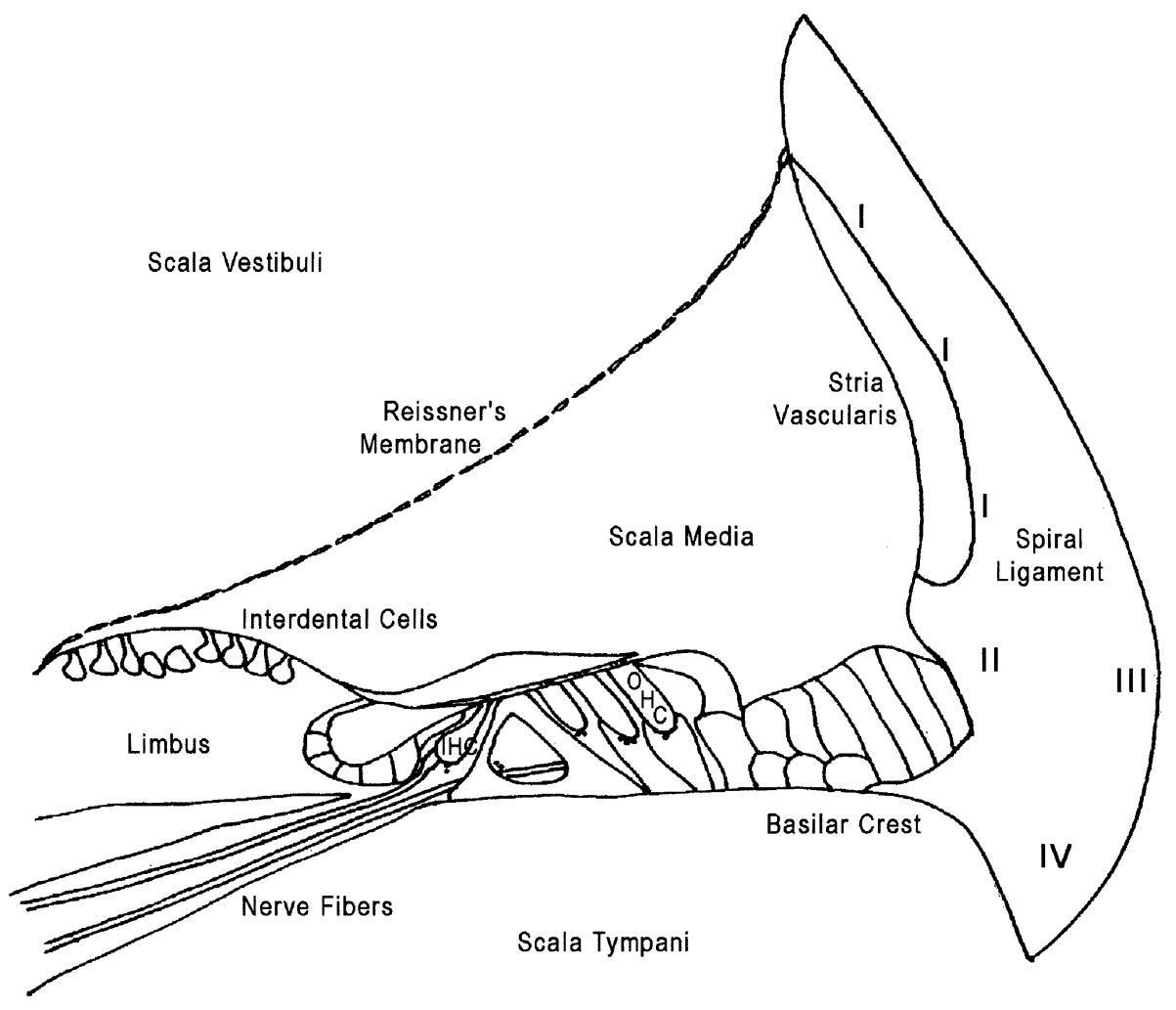

FIG. 7. Schematic diagram of a cross section of the cochlear duct showing the location criteria for classification of fibrocytes in the spiral ligament. Type I fibrocytes (I), beneath the stria vascularis; type II fibrocytes (II), superficial between the basilar crest and the stria vascularis; type III fibrocytes (III), adjacent to the otic capsule; type IV fibrocytes (IV), inferior to basilarmembrane near scala tympani.
Here, ears that were allowed to recover for two weeks after chronic furosemide application reacquired significant function with regard to EP values and CAP thresholds. Recovery after acute systemic treatment with furosemide takes only a few minutes or hours (Forge 1976; Sewell 1984; Rybak 1985; Ikeda et al. 1997). However, EP and CAP measures in our lab showed little recovery $6-24 \mathrm{~h}$ after chronic treatment (data not shown). Compared with previous acute experiments, the chronic furosemide model can provide relatively long periods of moderate EP reduction. The moderate reduction may be the trigger for increasing the proliferation of fibrocytes in the spiral ligament as a self-protective reaction or homeostatic mechanism to regain normal values of EP.

\section{Intermediate cell proliferation}

Roberson and Rubel (1994) reported that cell division was enhanced in the stria vascularis of the developing gerbil after acoustic trauma. Basal, marginal, intermediate, and capillary endothelial cells were all seen to divide. Cell proliferation was especially apparent in regions where damage to the organ of Corti was most severe. Thus, with acoustic trauma, the increased proliferation extended to many cell types and presumably represented an attempt to repair damaged tissue. Our results with furosemide treatment differ from those produced by acoustic trauma. While intermediate cells showed low rates of cell division in control tissue, this rate did not increase after furosemide treatment. Only spiral ligament fibrocytes significantly increased their turnover rate after treatment. Thus, cell proliferation in the cochlea seems dependent on the specific trauma involved as well as, perhaps, its mechanism of delivery and duration.

Caution must be used in quantifying proliferation among intermediate cells. Increased pigmentation in the stria has been observed in many studies after cochlear trauma (Gratacap et al. 1985; Gratton and Wright 1992; Shaddock et al. 1985). The melanosomes and melanin pigment can easily be mistaken for positive staining with BrdU and even with radioautographic techniques, making the counting of dividing cells problematic. We found it imperative to bleach the stria vascularis to get a true estimate of intermediate cell division. To our knowledge, bleaching the stria vascularis has not been done in previous studies.

Type II and type IV fibrocytes in the aged ear

Another important finding was the significant decrease in fibrocyte proliferation found in the spiral ligament of the aged cochlea. Decreased mitosis was significant only in type II and IV fibrocytes. Decreased turnover of spiral ligament fibrocytes may be related to the decrease of ion-transport enzymes found in the lateral wall of aged animals. For example, Na,K-AT- 

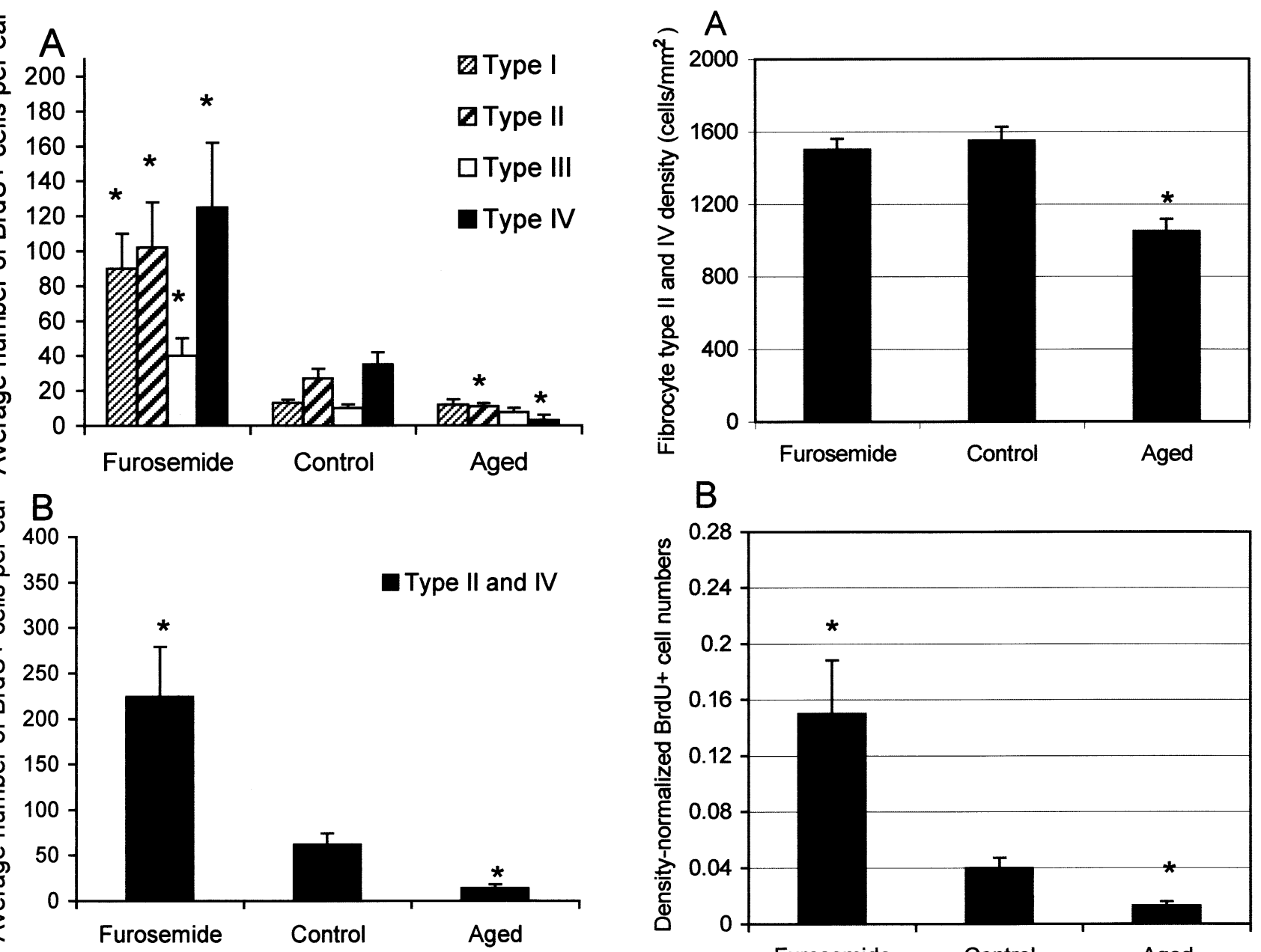

FIG. 8. A. Average numbers of BrdU+ cells within various fibrocyte subtypes in the spiral ligament. Data are from the same ears as Fig. $6 \mathrm{~B}$ and have been normalized to one ear. Means $( \pm$ SEM) are from six furosemide-treated, six young control, and five aged ears. Numbers of proliferating cells in all fibrocyte subtypes in the furosemidetreated group were significantly greater than those in young controls; however, only type II and IV fibrocytes were significantly smaller in the aged group as compared with young controls (ANOVA, $p<$ 0.05). B. Average numbers of BrdU+ type II and IV fibrocytes in the spiral ligament as normalized to one ear. Data are from the same animals shown in A.Numbers of proliferating type II and IV fibrocytes in the furosemide-treated group were increased significantly over those from young controls; conversely, the numbers of proliferating type II and IV fibrocytes in the aged group were significantly less than those found in young controls (ANOVA, $p<0.05$ ).

Pase immunostaining is significantly reduced in type II and IV fibrocytes in aged cochleas (Schulte and Schmiedt 1992; Spicer et al. 1997). Decreased cell turnover in type II and IV fibrocytes could lead to fewer surviving cells and could be responsible for the reduced immunostaining for $\mathrm{Na}, \mathrm{K}-\mathrm{ATP}$ ase in the spiral ligament of the aged gerbil. Thus, decreased cell proliferation with age may play an essential role in metabolic presbyacusis with its associated loss of EP.

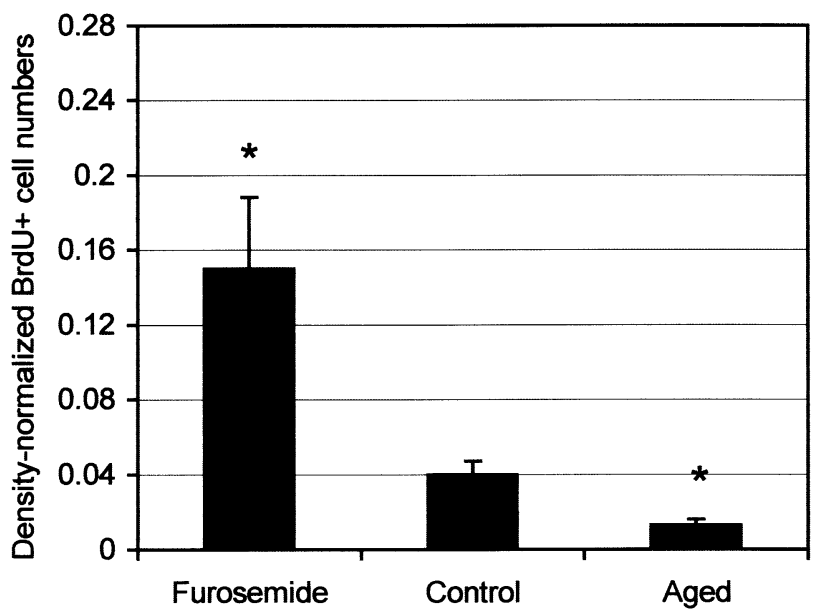

FIG. 9. A. Cell densities of type II and IV fibrocytes in the spiral ligaments of furosemide-treated, control, and aged gerbils. Data are from the same animals shown in Fig. 8. Cell density of type II and IV fibrocytes in the aged group was significantly less than that in young controls (ANOVA, $p<0.05$ ); however, there was no significant differencebetween the furosemide-treated and young control groups (ANOVA, $p>0.05$ ). B. The cell-proliferating index of type II and IV fibrocytes as normalized to cell density. Even when cell density is controlled, there was still a significant increase in cell proliferation in type II and IV fibrocytes in the furosemide-treated group compared with young controls (ANOVA, $p<0.05$ ). Similarly, the proliferation of type II and IV fibrocytes was significantly reduced in the aged group as compared to young controls (ANOVA, $p<0.05$ ).

\section{ACKNOWLEDGMENTS}

The authors thank Boo Schmiedt and Nancy Smythe for their technical assistance. This work was supported by NIH/ NIA RO1 AG/14748 (RAS) and NIH/NIDCD R01 DC00713 (BAS).

\section{REFERENCES}

Conlee JW, Gerity LC, Bennett ML. Ongoing proliferation of melanocytes in the stria vascularis of adult guinea pigs. Hear. Res. 79:115-122, 1994. 
Crouch JJ, Sakaguchi N, Lytle C, Schulte BA. Immunohistochemical localization of the Na-K-Cl co-transporter (NKCC1) in the gerbil inner ear. J. Histochem. Cytochem. 45:773-778, 1997.

Forge A. Observations on the stria vascularis of the guinea pig cochlea and the changes resulting from the administration of the diuretic furosemide. Clin. Otolaryngol. 1:211-219, 1976.

Franz P, Aharinejad S, Firbas W. Melanocytes in the modiolus of the guinea pig cochlea. Acta Otolaryngol. 109:221-227, 1990.

Gratacap B, Charachon R, Stoebner P. Results of an ultrastructural study comparing stria vascularis with organ of Corti in guinea pigs treated with kanamycin. Acta Otolaryngol. (Stockh.) 99: 339-342, 1985.

Gratton MA, Wright CG. Hyperpigmentation of chinchilla stria vascularis following acoustic trauma. Pigment. Cell. Res. 5:3037, 1992.

Gratton MA, Schmiedt RA, Schulte BA. Age-related decreases in the endocochlear potential are associated with vascular abnormalities in the stria vascularis. Hear. Res. 102:181-190, 1996.

Gratton MA, Schulte BA, Smythe NM. Quantification of the stria vascularis and strial capillary areas in quiet-reared young and aged gerbils. Hear. Res. 114 (1-2):1-9, 1997.

HALL RD. Estimation of surviving spiral ganglion cells in the deaf rat using the electrically evoked auditory brainstem response. Hear. Res. 45:123-136, 1990.

Hall RD, Massengill JL. The number of primary auditory afferents in the rat. Hear. Res. 103:75-84, 1997.

Hellstrom LI, Schmiedt RA. Compound action potential input/ output functions in young and quiet-aged gerbils. Hear. Res. 50:163-174, 1990.

Hellstrom LI, Schmiedt RA. Measures of tuning and suppression in single-fiber and whole-nerve responses in young and quietaged gerbils. J. Acoust. Soc. Am. 100:3275-3285, 1996.

Hequembourg S, Liberman MC. Spiral ligament pathology: a major aspect of age-related cochlear degeneration in C57BL/ 6 mice. J. Assoc. Res. Otolaryngol. 02:118-129, 2001.

Hilding DA, Ginzberg RD. Pigmentation of the stria vascularis. The contribution of neural crest melanocytes. Acta Otolaryngol. (Stockh.) 84:24-37, 1977.

Ikeda K, Oshima T, Hidaka H, Takasaka T. Molecular and clinical implications of loop diuretic ototoxicity. Hear. Res. 107:1-8, 1977.

Kikuchi T, Kimura RS, Paul DL, Adams JC. Gap junctions in the rat cochlea: immunohistochemical and ultrastructural analysis. Anat. Embryol. (Berl.) 191:101-118, 1995.

Kikuchi T, Kimura RS, Paul DL, Takasaka T, Adams JC. Gap junction systems in the mammalian cochlea. Brain. Res. Brain. Res. Rev. 32:163-166, 2000.

La Ferriere KA, Arenberg IK, Hawkins JE, Johnsson LG. Melanocytes of the vestibular labyrinth and their relationship to the microvasculature. Ann. Otol. Rhinol. Laryngol. 83:685-694, 1974.

Lang H, Bever MM, Fekete DM. Cell proliferation and cell death in the developing chick inner ear: spatial and temporal patterns. J. Comp. Neurol. 417:205-220, 2000.

Li LX, Crotty KA, Kril JJ, Palmer AA, McCarthy SW. Method of melanin bleaching in MIB1-Ki67 immunostaining of pigmented lesions: A quantitative evaluation in malignant melanomas. Histochem. J. 131:237-240, 1999.

Minowa O, Ikeda K, Sugitani Y, Oshima T, Naka S, Katori Y, Suzuki M, Furukawa M, Kawase T, Zheng Y, Ogura M, Asada Y, Watanabe K, Yamanaka H, Gotoh S, Nishi-Takeshima M, Sugimoto T, KikUchi T, TAKasaka T, Noda T. Altered cochlear fibrocytes in a mouse model of DFN3 nonsyndromic deafness [see comments]. Science 285:1408-1411, 1999.

MÜller M. The cochlear place-frequency map of the adult and developing Mongolian gerbil. Hear Res. 94:148-156, 1996.
Okamura H, Schmiedt RA, Spicer S, Schulte B. Morphologic and physiologic changes in gerbil cochleas induced by chronic exposure to furosemide. Assoc. Res. Otolaryngol. Abstr. 23:126, 2000.

Roberson D, Rubel EW. Cell division in the gerbil cochlea after acoustic trauma. Am. J. Otol. 15 (1):28-34, 1994.

Ruben RJ. Development of the inner ear of the mouse: a radioautographic study of terminal mitoses. Acta Otolaryngol. Suppl. (Stockh.) 220:1-44, 1967.

Ryвak LP. Furosemide ototoxicity: clinical and experimental aspects. Laryngoscope 95:1-14, 1985.

Sakaguchi N, Crouch JJ, Lytle C, Schulte BA. Na-K-Cl cotransporter expression in the developing and senescent gerbil cochlea. Hear. Res. 118:114-122, 1998.

SAVIN C. The blood vessels and pigmentary cells of the inner ear. Ann. Otol. Rhinol. Laryngol. 74:611-623, 1965.

SCHmiedt RA. Does the aging cochlea need a jump-start? In: Verrillo RT (ed) Sensory Research Multimodal Perspectives. Erlbaum and Associates, New York, 1993, pp 91-103

SCHMiEDT RA. Effects of aging on potassium homeostasis and the endocochlear potential in the gerbil cochlea. Hear. Res. 102:125-132, 1996.

SCHMiedt RA, ZwisLocki JJ. Comparison of sound-transmission and cochlear-microphonic characteristics in Mongolian gerbil and guinea pig. J. Acoust. Soc. Am. 61:133-149, 1997.

Schmiedt RA, Schulte BA. Physiologic and histopathologic changes in quiet- and noise-aged gerbil cochleas. In: Dancer A, Henderson D, Salvi R, Hamernik R (eds) Noise Induced Hearing Loss Mosby Yearbook Inc., St. Louis, MO, 1992, pp 246-256

Schmiedt RA, LANG H. Presbyacusic thresholds: a consequence of an energy-starved cochlear amplifier. Assoc. Res. Otolaryngol. Abstr. 24:148, 2001.

Schmiedt RA, Mills JH, Adams JC. Tuning and suppression in auditory nerve fibers of aged gerbils raised in quiet or noise. Hear. Res. 45:221-236, 1990.

Schmiedt RA, Mills JH, Boettcher FA. Age-related loss of activity of auditory-nerve fibers. J. Neurophysiol. 76:799-803, 1996.

Schmiedt RA, Spicer SS, Schulte BA. Morphologic and physiologic changes in gerbil cochleas exposed to chronic infiltration of furosemide into perilymph. Assoc. Res. Otolaryngol. Abstr. 22:134, 1999.

Schmiedt RA, Lang H, Okamura H. Model of metabolic presbyacusis: Neural responses under condition of chronically-low endocochlear potentials induced with furosemide. Assoc. Res. Otolaryngol. Abstr. 23:282, 2000.

Schmiedt RA, Lang H, Okamura H, Schulte BA. Effects of furosemide applied chronically to the round window: a model of metabolic presbyacusis. J. Neurosci. 22:9643-9650, 2002.

Schuknecht HF, Gacek MR. Cochlear pathology in presbyacusis. Ann. Otol. Rhinol. Laryngol. 102:1-16, 1993.

Schulte BA, AdAms JC. Distribution of immunoreactive $\mathrm{Na}^{+}, \mathrm{K}^{+}-$ ATPase in gerbil cochlea. J. Histochem. Cytochem. 37:127-134, 1989.

Schulte BA, Schmiedt RA. Lateral wall Na,K-ATPase and endocochlear potentials decline with age in quiet-reared gerbils. Hear. Res. 61:35-46, 1992.

SEwELL W. The effects of furosemide on the endocochlear potential and auditory-nerve fiber tuning curves in cats. Hear. Res. 14:305-314, 1984.

Shaddock LC, Wright CG, Hamernik RP. A morphometric study of microvascular pathology following experimental rupture of Reissner's membrane. Hear. Res. 20:119-129, 1985.

Spicer SS, Schulte BA. Differentiation of inner ear fibrocytes according to their ion transport related activity. Hear. Res. 56:5364, 1991. 
SPICER SS, Schulte BA. The fine structure of spiral ligament cells relates to ion return to the stria and varies with place-frequency. Hear. Res. 100:80-100, 1996.

Spicer SS, Gratton MA, Schulte BA. Expression patterns of ion transport enzymes in spiral ligament fibrocytes change in relation to strial atrophy in the aged gerbil cochlea. Hear. Res. 111:93-102, 1997.
TAKAHASHI T, KIMURA RS. The ultrastructure of the spiral ligament in the Rhesus monkey. Acta Otolaryngol. (Stockh.) 69:46-60, 1970.

WolfF D. Melanin in inner ear. Arch. Otolaryngol. 14:195-211, 1931. Yamashita H, Shimogori H, Sugahara K, Takahashi M. Cell proliferation in spiral ligament of mouse cochlea damaged by dihydrostreptomycin sulfate. Acta Otolaryngol. 119:322-325, 1999. 